\title{
Physiological Effects of Smoke Exposure on Deciduous and Conifer Tree Species
}

\author{
W. John Calder, ${ }^{1}$ Greg Lifferth,, ${ }^{1}$ Max A. Moritz, ${ }^{2}$ and Samuel B. St. Clair ${ }^{1}$ \\ ${ }^{1}$ Department of Plant and Wildife Sciences, Brigham Young University, Provo, UT 84602, USA \\ ${ }^{2}$ Department of Environmental Science, Policy, and Management, University of California, Berkeley, CA 94720, USA
}

Correspondence should be addressed to Samuel B. St. Clair, samuel_stclair@byu.edu

Received 1 July 2009; Revised 6 December 2009; Accepted 1 February 2010

Academic Editor: Terry L. Sharik

Copyright (C) 2010 W. John Calder et al. This is an open access article distributed under the Creative Commons Attribution License, which permits unrestricted use, distribution, and reproduction in any medium, provided the original work is properly cited.

\begin{abstract}
Smoke from forest fires can persist in the environment for weeks and while there is a substantial amount of literature examining the effects of smoke exposure on seed germination, the effects of smoke on leaf function are nearly uninvestigated. The objective of this study was to compare growth and primary and secondary metabolic responses of deciduous angiosperm and evergreen conifer tree species to short smoke exposure. Twenty minutes of smoke exposure resulted in a greater than $50 \%$ reduction in photosynthetic capacity in five of the six species we examined. Impairment of photosynthesis in response to smoke was a function of reductions in stomatal conductance and biochemical limitations. In general, deciduous angiosperm species showed a greater sensitivity than evergreen conifers. While there were significant decreases in photosynthesis and stomatal conductance, smoke had no significant effect on growth or secondary defense compound production in any of the tree species examined.
\end{abstract}

\section{Introduction}

Fire has shaped terrestrial plant communities for the last 350 million years [1]. In the Intermountain West, fire has had an integral role in structuring plant communities with typical fire return intervals between 35 and 200 years [2]. Smoke produced from fires varies with the fuel loads, intensity, and duration of burning, and can persist in the air for weeks [3]. A better understanding of the responses of plants to smoke is becoming increasingly more relevant as longer growing seasons and increased drought frequency and duration projected under future climate scenarios are expected to result in an increase in wildfires [4].

Nearly all of the studies that examine the effects of smoke on plant physiology and development have been tied to seed germination [5]. Relatively little is known about how smoke influences primary and secondary metabolism in plants. Davies and Unam [6] studied the effects of forest fires in Indonesia on photosynthesis and found that despite increases in $\mathrm{CO}_{2}$ from the fires, photosynthetic rates were lowered. Gilbert and Ripley [7] showed that smoke exposure reduced stomatal conductance, $\mathrm{CO}_{2}$ assimilation rate, and intercellular leaf $\mathrm{CO}_{2}$ concentrations.
In theory, smoke could reduce photosynthesis through physical and/or chemical processes. Physically, smoke production can lead to high-vapor pressure deficits that can trigger stomatal closure [8]. Chemically, over 100 compounds have been identified in smoke [9]. Of those that have been identified, many are known to have physiologically effects on plants, including $\mathrm{NO}_{2}[10], \mathrm{CO}_{2}, \mathrm{SO}_{2}$, and $\mathrm{O}_{3}$ [11]. $\mathrm{O}_{3}$ has been linked to the destruction of chlorophyll [12] and has also been shown to inhibit the $\mathrm{K}^{+}$channels that regulate guard cell function and in turn controls stomatal opening [13]. $\mathrm{SO}_{2}$ reduces stomatal conductance [14], inhibits photosynthetic oxygen evolution and electron transport, and inactivates Calvin-cycle enzymes [15-17]. When combined, $\mathrm{NO}_{2}$ and $\mathrm{SO}_{2}$ mixtures have shown to additively inhibit photosynthesis [18]. Long-term exposures to $\mathrm{NO}_{2}$ and $\mathrm{SO}_{2}$ show subsequent reductions in superoxide dismutase and glutathione reductase [19], which are major antioxidant enzymes in plants $[19,20]$. The disabling of antioxidant enzyme function in conjunction with high levels of ozone, a powerful pro-oxidant, may promote oxidative stress during extended smoke exposure.

Changes in environmental conditions following a fire can reduce biotic stress pressure experienced by plants. Moritz 
and Odion [21] found a strong relationship between the absence of infection of Phytophthora ramorum and time since last burn. They suggested that fire may inhibit pathogen activity by increasing the availability of $\mathrm{Ca}$, which is crucial for plant resistance to disease [22]. Drier microclimates following fire can limit fungal pathogen growth [23], and Schwartz et al. [24] proposed that the fungicidal properties of smoke reduced fungal infection and growth on leaves [24].

Smoke is a highly complex chemical cocktail with plant active compounds that can provide information to plants in ecosystems that have recently experienced fire. For example, smoke is used as a cue by seeds in some fire adapted plant species as a signal that conditions are favorable for germination, for example, [25]. Butenolide 3-methyl$2 \mathrm{H}$-furo[2,3-c]pyran-2-one is a compound in smoke that induces germination [26]. It is unknown how the seed perceives the butenolide but there is evidence that it triggers germination by facilitating uptake of water [27]. As there are many changes in environmental conditions after a fire (e.g., reduction in competition, nutrient pulses in the soil and decreased pathogen loads), plants may use smoke as an environmental cue to initiate other adaptive metabolic and growth responses.

Condensed tannins and phenolic glycosides are foliar defense compounds that plants often produce in very high concentrations (up to $30 \%$ dry weight in some species) to defend themselves against herbivory and pathogen attack $[28,29]$. Allocation of resources to defense chemistry production results in a tradeoff where growth potential is reduced $[30,31]$. Plasticity in defense chemistry production in response to shifts in environmental conditions has been demonstrated $[32,33]$. In a postfire scenario, a reduction in pathogen and insect pressure may result in a reduced need for high levels of secondary defense compounds and thereby allow for a greater resource allocation to growth and reproduction.

Here we investigate the responses of three deciduous angiosperm (Populus tremuloides, Acer glabrum, Quercus gambelii) and three evergreen conifer (Pinus ponderosa, Pseudotsuga menziesii, and Picea pungens) tree species to shortterm smoke exposures. We hypothesize that: (1) exposure to smoke reduces rates of photosynthesis and stomatal conductance; (2) smoke serves as a signal that results in the allocation of seedling resources away from defense chemistry production to growth.

\section{Materials and Methods}

Six tree species (Populus tremuloides, Acer glabrum, Quercus gambelii, Pinus ponderosa, Pseudotsuga menziesii, and Picea pungens) in their second year of growth were used as treatment units. These species were chosen because they have adaptations that allow them to survive fire through resistance or regeneration, which indicates they have evolved in response to fire. Populus tremuloides (quaking aspen), Acer glabrum (Rocky Mountain maple), and Quercus gambelii (gamble oak) respond to fire with resprouting through root suckers [34-36]. Evergreen conifer species such as
Pinus ponderosa (ponderosa pine) and Pseudotsuga menziesii (Douglas-fir) employ a strategy of fire resistance with their thick bark [37]. Picea pungens (blue spruce) is not known for fire resistance but it is useful as another evergreen conifer species that regularly experiences fire. All of these species are common in the Rocky Mountains and are ecologically important species. Populus tremuloides was grown from wild root cuttings from a common clone, and the remaining five species were obtained from two tree nurseries (Sun Mountain growers, in Kaysville, Utah, and Plants of the Wild, Tekoa, Washington) as potted and bare root seedlings.

Prior to planting, seedling roots were washed and fresh weight plant mass was measured. Within each species, trees of uniform mass and height were used in the study. On March 26-27, 2008, each tree was transplanted into a peat/perlite $(3: 1)$-based medium of $75 \%-80 \%$ Canadian Sphagnum peat moss with gypsum, perlite, limestone and wetting agent (Sunshine Mix \#1, Sun Gro Horticulture, Bellevue, WA) in pots $23.5 \mathrm{~cm} \times 11.5 \mathrm{~cm}^{2}$. Four grams of Osmocote Smart Release Plant Food with 14-14-14 were added to each pot to provide necessary nutrients for growth. The trees were in a climate controlled greenhouse for the remainder of the summer and were watered to saturation twice a week.

2.1. Smoke Treatment. From May 26-30, 2008, five replicate seedlings of each species were exposed to smoke staggered across time (one replicate each day, over a five-day period). Smoke exposure occurred for 20 minutes. A second cycle of smoke exposure on the same plants occurred from June 9$13,2008$.

The smoke chamber was fabricated from a sealed plastic cooler $(95 \mathrm{~cm} \times 38 \mathrm{~cm} \times 45 \mathrm{~cm})$. Equal parts of dried leaf material obtained from each of the six tree species in the study were used to generate the smoke. The leaves were combusted in a glass funnel fitted into a flask that was connected to the top of a glass flask. The flask was cooled in an ice bath to eliminate temperature increases inside the chamber. For 25 seconds, $500 \mathrm{mg}$ of leaf material mixture were burned to ash with a butane lighter and the smoke was pulled through plastic tubing into the chamber using a vacuum connected to tubing at the bottom of the cooler. A fan inside the cooler dispersed the smoke and a florescent light inside the cooler provided low light levels. Temperatures inside of the smoke chamber never exceeded $35^{\circ} \mathrm{C}$, as measured by a Hobo U10-003 data logger (Onset Computer Corporation, Pocasset, MA). A second chamber identical to the first was used for control treatments. All procedures were exactly the same for the control chamber with the exception that leaf material was not placed in the glass funnel.

It is difficult to compare our smoke exposure with what is experienced in natural settings as smoke production is extremely variable in western North America [3]. This is due in part to variations in fuel load, fuel consumption, rate of emissions, and dispersion rates [38]. Mixed conifer forest fuel loads can vary from 63-112 $\mathrm{MT} \mathrm{ha}^{-1}$ and aspens forests from 20-83 $\mathrm{MT} \mathrm{ha}^{-1}$ [38]. As we used 0.03 $\mathrm{MT} \mathrm{ha}^{-1}$ (leaf 
mass $\times$ area of smoke chamber), we estimate that our smoke exposure is less concentrated than what is experienced in a forest fire.

2.2. Gas Exchange. After smoke exposure, the treated plants were removed from the smoke chamber to measure rates of photosynthesis and stomatal conductance with a gas exchange system (LI-COR 6400, Li-Cor Biosciences, Lincoln, $\mathrm{NE}$ ). Photosynthetic measurements were taken at a photosynthetic photon flux density (PPFD) of $1200 \mu \mathrm{mol} \mathrm{m}^{-2} \mathrm{~s}^{-1}$ with the 6400-04 LED blue-red light source at ambient temperature and humidity. Two measurements were taken at $\mathrm{CO}_{2}$ concentrations of $385 \mathrm{ppm}$ and $1000 \mathrm{ppm}$, respectively, with $\mathrm{CO}_{2}$ concentrations being achieved using the $\mathrm{CO}_{2}$ mixer to distinguish whether smoke effects on photosynthesis were related to stomatal and/or biochemical limitations [39]. Measurements were initiated by sealing the leaf in the chamber on the youngest fully expanded leaf or needles of each tree. After $\mathrm{CO}_{2}$ and water vapor concentrations in the leaf chamber reached a steady state (60-90 seconds), rates of photosynthesis and stomatal conductance were logged. Measurements were taken immediately after smoke exposure, 30 minutes after exposure, and then every 70 minutes until 310 minutes thereafter.

To calculate leaf area for leaves that did not fill the leaf chamber, leaves were traced on paper which was cut out and then measured for area with the leaf area meter ( $\mathrm{Li}-$ Cor 3000, Li-Cor Biosciences, Lincoln, NE, USA). Needle area was calculated by scanning an image of the needles and measuring area with Scion Image for Windows (Frederick, Maryland, USA).

2.3. Growth. On July 29, 2008, the trees were harvested for growth and mass measurements. Stem height was measured and then the seedling was cut off at soil level and both roots and shoots were dried at $60^{\circ} \mathrm{C}$ for 72 hours to obtain dry mass using an analytical balance (GeneMate GP-600, ISC Bioexpress, Kaysville, UT, USA).

2.4. Secondary Chemistry. Leaves and needles were removed from the seedlings nine weeks after smoke exposure (July 29,2008 ) and packed on dry ice before being moved to storage at $-80^{\circ} \mathrm{C}$ for later analysis of phenolic glycosides and condensed tannins. Leaves were freeze dried and needles were oven dried at $60^{\circ} \mathrm{C}$ for 72 hours. Leaf and needle material was then crushed in a Wiley Mill using a no. 10 screen. Tannins were quantified for all species using a modified butanol-HCL method described in Porter et al. [40], where approximately $50 \mathrm{mg}$ of leaf material were placed in $2 \mathrm{~mL}$ screw-cap microcentrifuge tubes suspended in $1 \mathrm{~mL}$ of $70 \%$ acetone- $10 \mathrm{mM}$ ascorbic acid solution. The samples were then vortexed on high at $4^{\circ} \mathrm{C}$ for 20 minutes. The liquid supernatant was then removed and the extraction was repeated. The concentration of tannins was then quantified spectrophotometrically (SpectraMax Plus 384, MDS, Toronto, Canada) using purified tannins as a standard.
The phenolic glycosides, salicortin and tremulacin, were extracted from approximately $50 \mathrm{mg}$ of aspen leaf tissue (the other species do not contain significant levels of phenolic glycosides). The tissue samples were placed in $2 \mathrm{~mL}$ screw cap micro-centrifuge tubes and suspended in methanol. The samples were then vortexed on high for 5 minutes. The liquid supernatant was removed and the extraction was repeated. Final concentrations of salicortin and tremulacin were quantified using high-performance liquid chromatography (Agilent 1100 Series, Santa Clara, CA, USA) with a Luna 2, C18 column $(150 \times 4.6 \mathrm{~mm}, 5 \mathrm{um})$ at a flow rate of $1 \mathrm{~mL} / \mathrm{min}$. Compound peaks were detected using a UV lamp at a wavelength of $280 \mathrm{~nm}$ with purified salicortin and tremulacin standards isolated from aspen leaves [41].

2.5. Statistical Analysis. We ran a Student's $t$-test to test for differences in defense chemistry and growth. Repeated measures analysis of variance (ANOVA) was used to test the effects of smoke exposure on rates of photosynthesis from 30 minutes after exposure to 310 minutes after exposure using time as the "within" factor [42]. Homogeneity of variance and normality were tested with Shapiro-Wilk W statistics and equal variance tests. Data that did not meet the assumptions for the parametric tests were tested using a Wilcox rank sum test, while the data in the graphs and tables were untransformed. Statistical analysis was performed using JMP version 7 statistical software (SAS Institute, Cary, NC, USA).

\section{Results}

All of the species showed significant differences in stomatal conductance and rates of photosynthesis 30 minutes after exposure, except for Douglas-fir. Aspen and ponderosa pine showed the greatest reductions in photosynthesis (Figure 1). Douglas-fir initially showed a significant decrease in $A_{\max }$ and $g_{s}$ (data not shown). Two weeks after exposure, rates of photosynthesis were measured again and there was a complete recovery in all species (data not shown).

The repeated measures analysis on rates of photosynthesis at $1000 \mathrm{ppm}, \mathrm{CO}_{2}$ showed a significant time effect $(P-$ value $<0.001)$ in which rates of photosynthesis recovered from smoke exposure as time progressed (Figure 2). At $1000 \mathrm{ppm}$ there was also a significant interaction between time and species type (deciduous angiosperms and evergreen conifer $)(P$-value $=.0073)$ with deciduous angiosperm species showing slower recovery (Figure 2). At $385 \mathrm{ppm} \mathrm{CO}_{2}$, time was the only significant effect in the repeated measures model $(P$-value $=.0209)$. Species type was marginally significant $(P$-value $=.0709)$.

There were no significant differences for growth, condensed tannins, or phenolic glycosides (Figure 3; data not shown for the latter).

\section{Discussion}

The data are consistent with our first hypothesis that smoke exposure reduces rates of photosynthesis. Comparing 


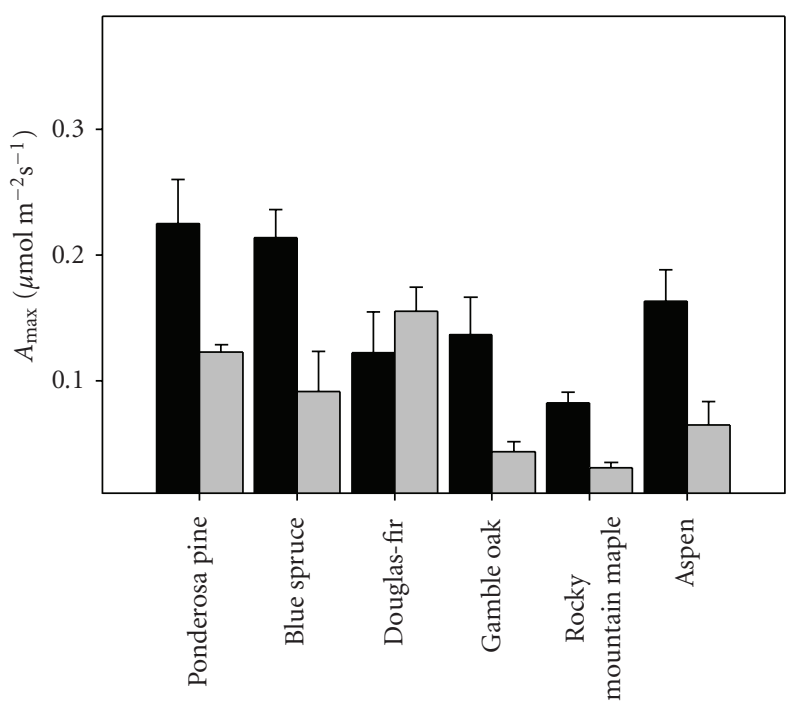

(a)

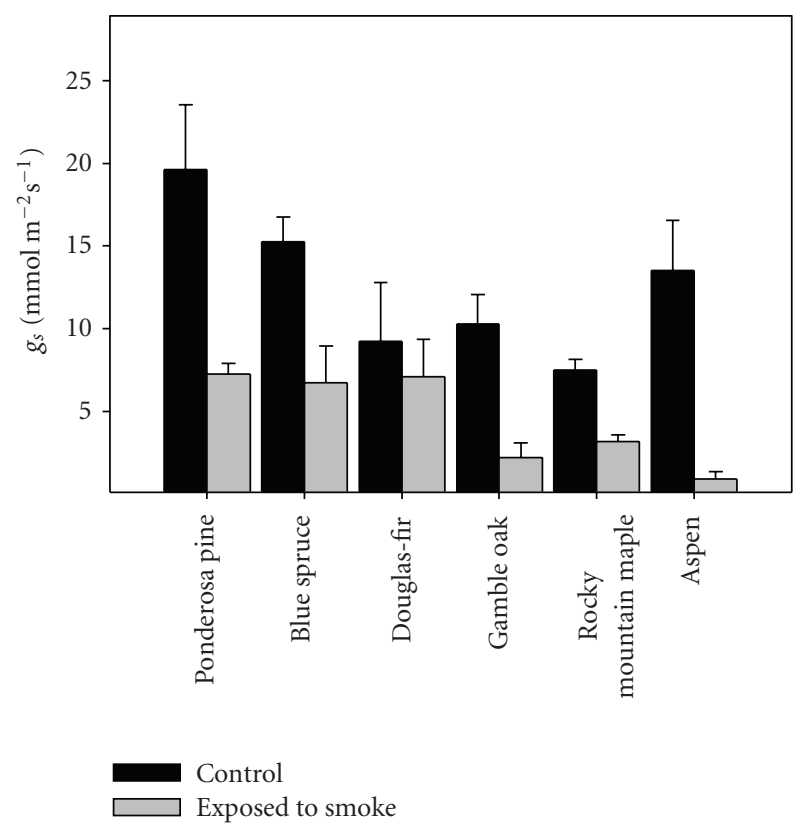

(b)

Figure 1: $A_{\max }$ (maximum rate of photosynthesis) and $g_{\mathrm{s}}$ (stomatal conductance) after 30 minutes of smoke exposure. The only species without significant differences between treatments (at $\alpha<0.05$ level) was Douglas-fir.

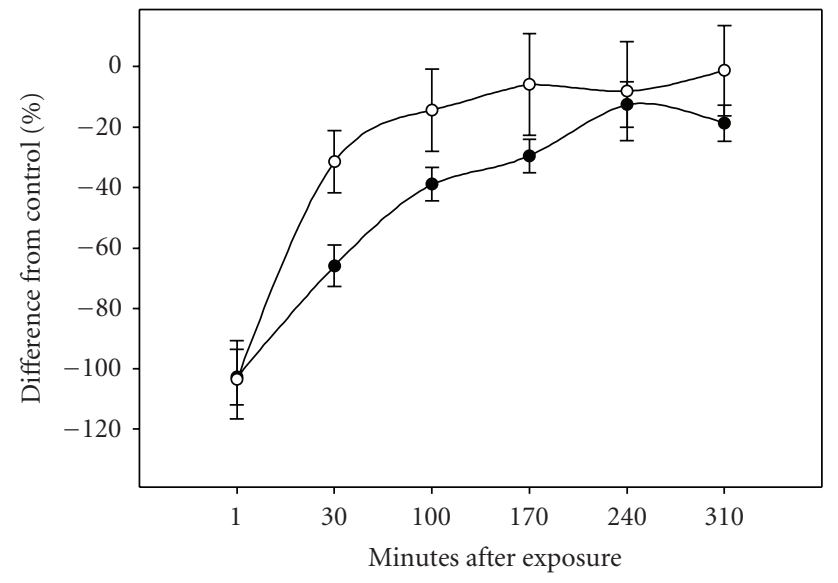

$\rightarrow$ Deciduous

$\multimap$ Coniferous

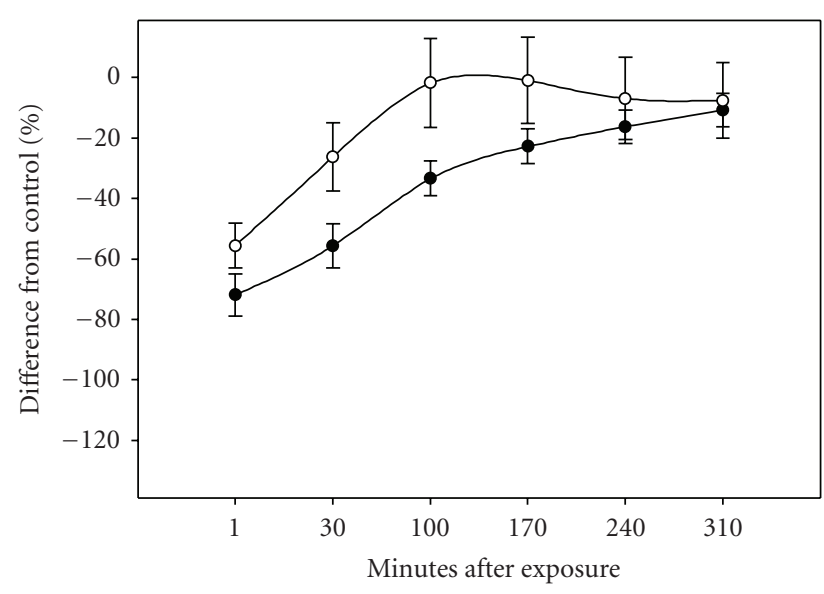

(b)

Figure 2: Decreased rates of photosynthesis expressed as percent difference from control at both ambient (a) ( $385 \mathrm{ppm}$ ) and saturating (b) (1000 ppm) $\mathrm{CO}_{2}$ concentrations.

photosynthetic responses at ambient and saturating $\mathrm{CO}_{2}$ concentrations suggests that smoke affects photosynthetic function by reducing stomatal conductance and through impairment of biochemical function (Figure 2). Our results show for the first time that photosynthetic sensitivity to smoke occurs across a diverse sampling of tree species and that there is wide-ranging variation in sensitivity between those species.
Because of the complexity of smoke constituents, it is hard to pinpoint which chemicals may be adversely affecting photosynthesis. Different compounds in smoke, such as NO and $\mathrm{NO}_{2}$, affect plant species to varying degrees [43]. We found that the evergreen conifers initially recovered from the smoke exposure faster than the deciduous angiosperms (Figure 2). Thirty minutes after smoke treatments had ended, only Douglas-fir had recovered completely (initial decreased 


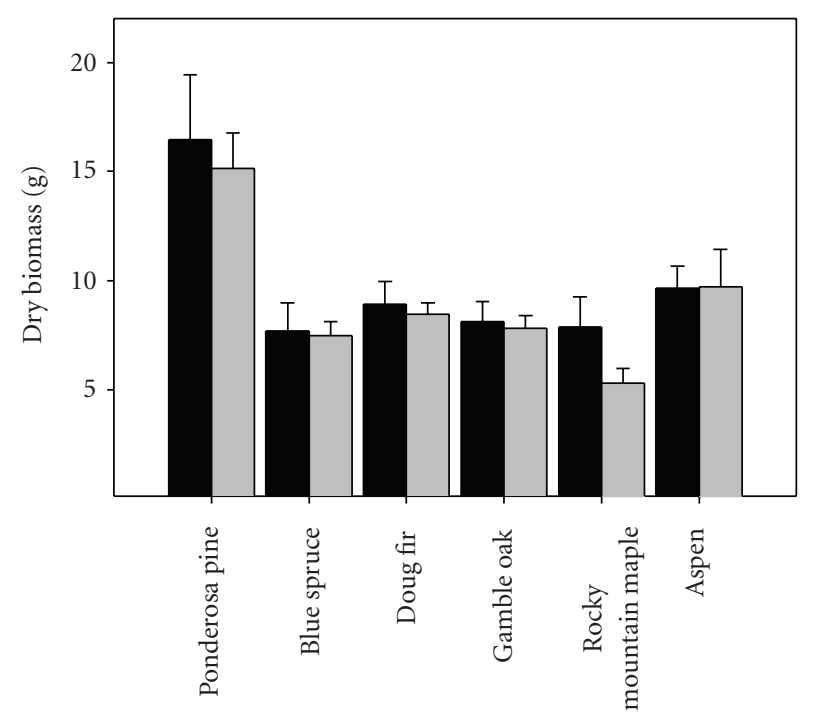

(a)

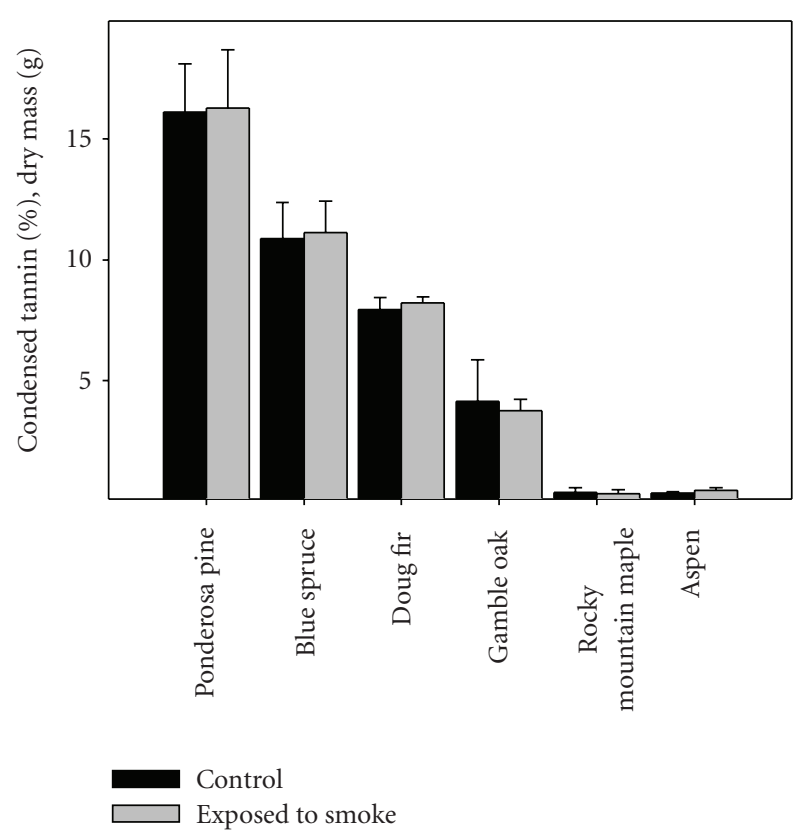

(b)

FIGURE 3: Comparisons of biomass and condensed tannins in smoke-exposed samples and controls. There were no significant differences between treatments of any species.

rates of photosynthesis not shown) (Figure 1). Though evergreen conifers recovered faster than the deciduous angiosperms, there were no changes in growth patterns or defense chemistry production in response to smoke exposures (Figure 3 ). This indicates that there were no long-term effects from our relatively short 20-minute smoke exposures.

Why the evergreen conifers initially recovered faster than the deciduous angiosperms is unknown. Plant species can develop tolerance to pollutants that are known to affect photosynthesis $[44,45]$. The greater tolerance in evergreen conifers could be a result of the different fire strategies, in which gamble oak, rocky mountain maple, and aspen employ a survival strategy of overstory morality followed by asexual regeneration at some later time [34-36]. In contrast, evergreen conifer species including ponderosa pine and Douglas-fir employ a strategy of fire resistance with their thick bark that allows the overstory to survive [37]. We hypothesize that species that employ a strategy of fire resistance would have a greater need to develop mechanisms of tolerance to avoid the negative effects of needle exposure to smoke for extended periods of time.

The results are inconsistent with second hypotheses that smoke alters growth patterns or allocation to defense chemistry. It is likely that two 20-minute smoke exposures are insufficient to elicit a growth response. In western North America, plants can be exposed to smoke on scales of weeks to months, as reviewed in [3]. Smoke exposures of such length are impractical in controlled studies but tree ring data could potentially be used to examine correlations between growth rates and smoke extent over the summer season if other confounding factors can be accounted for.
There are a few possible reasons why we did not find any significant differences in defense chemistry in response to smoke treatments. First, for aspen, it is known that different genotypes respond differently to environmental changes [29]. Here we only used one genotype and that could result in missing responses that occur in other aspen genotypes. Second, in contrast to seed germination, plants may not use smoke as a cue for physiological leaf responses following fire. Third, while we looked at two important defense compounds based on quantity and function, we certainly did not conduct a comprehensive survey of secondary metabolic responses. Finally, it is also possible that the signature of our smoke exposures (chemistry, timing, intensity) was not adequate for eliciting a defense response.

Because there are many compounds in smoke and we know so little about how they can affect plants, we have much to learn about the influence of smoke on plant function. The fact that different plant species can show varying responses to smoke, in addition to the potential for different plant species to produce their own complex suite of compounds, suggests there may be some intriguing roles for smoke in plant and ecosystem function.

\section{Acknowledgment}

Thanks are given to Joey Schmutz for helping plant and monitor the seedlings, Eric Smith for assistance in smoke exposure and sample processing, and Mitchell Calder for helping with harvesting. 


\section{References}

[1] J. K. Agee, Fire Ecology of Pacific Northwest Forests, Island Press, Washington, DC, USA, 1993.

[2] "Wildland fire in ecosystems: effects of fire on flora," in Introduction and Fire Regimes, J. K. Brown and J. K. Smith, Eds., United States Department of Agriculture, Forest Service, Ogden, Utah, USA, 2009.

[3] D. V. Sandberg, R. D. Ottmar, and J. L. Peterson, "Wildland fire in ecosystems: effects of fire on air," General Technical Report, U.S. Department of Agriculture, Forest Service, Ogden, Utah, USA, 2009.

[4] ICPP, Working Group 2 Fourth Assessment Report, Cambridge University Press, Cambridge, UK, 2007.

[5] M. I. Daws, J. Davies, H. W. Pritchard, N. A. C. Brown, and J. Van Staden, "Butenolide from plant-derived smoke enhances germination and seedling growth of arable weed species," Plant Growth Regulation, vol. 51, no. 1, pp. 73-82, 2007.

[6] S. J. Davies and L. Unam, "Smoke-haze from the 1997 Indonesian forest fires: effects on pollution levels, local climate, atmospheric $\mathrm{CO} 2$ concentrations, and tree photosynthesis," Forest Ecology and Management, vol. 124, no. 2-3, pp. 137-144, 1999.

[7] M. E. Gilbert and B. S. Ripley, "The effect of smoke on the photosynthetic gas exchange of Chrysanthemoides monilifera," South African Journal of Botany, vol. 68, no. 4, pp. 525$531,2002$.

[8] J. M. Guehl and G. Aussenac, "Photosynthesis decrease and stomatal control of gas exchange in Abies alba Mill. In response to vapor pressure difference," Plant Physiology, vol. 83, no. 2, pp. 316-322, 1987.

[9] M. Radojevic, "Chemistry of forest fires and regional haze with emphasis on Southeast Asia," Pure and Applied Geophysics, vol. 160, no. 1-2, pp. 157-187, 2003.

[10] J. E. Keeley and C. J. Fotheringham, "Trace gas emissions and smoke-induced seed germination," Science, vol. 276, no. 5316, pp. 1248-1250, 1997.

[11] M. F. Robinson, J. Heath, and T. A. Mansfield, "Disturbances in stomatal behaviour caused by air pollutants," Journal of Experimental Botany, vol. 49, Special Issue, pp. 461-469, 1998.

[12] G. D. Peiser and S.F. Yang, "Chlorophyll destruction by bisulfite-oxygen system," Plant Physiology, vol. 60, no. 2, pp. 277-281, 1977.

[13] G. Torsethaugen, E. J. Pell, and S. M. Assmann, "Ozone inhibits guard cell $\mathrm{K}^{+}$channels implicated in stomatal opening," Proceedings of the National Academy of Sciences of the United States of America, vol. 96, no. 23, pp. 13577-13582, 1999.

[14] T. W. Kimmerer and T. T. Kozlowski, "Stomatal conductance and sulfur uptake of five clones of Populus tremuloides exposed to sulfur dioxide," Plant Physiology, vol. 67, pp. 990995, 1981.

[15] A. R. Wellburb, "SO2 effects on stromal and thylakoid function," in Sulfur Dioxide and Vegetation, W. E. Winner, H. A. Mooney, and R. A. Goldstein, Eds., pp. 133-147, Stanford University Press, Stanford, Calif, USA, 1985.

[16] K.-I. Shimazaki, K. Nakamachi, N. Kondo, and K. Sugahara, "Sulfite inhibition of Photosystem II in illuminated spinach leaves," Plant and Cell Physiology, vol. 25, no. 2, pp. 337-341, 1984.

[17] K. Shimazaki and K. Sugahara, "Specific inhibition of photosystem II activity in chloroplasts by fumigation of spinach leaves with SO2," Plant and Cell Physiology, vol. 20, no. 5, pp. 947-955, 1979.

[18] J. N. Bull and T. A. Mansfield, "Photosynthesis in leaves exposed to SO2 and NO2," Nature, vol. 250, no. 5465, pp. 443444, 1974.

[19] G. Wingsle and J. Hallgren, "Influence of SO2 and NO2 exposure on glutathione, superoxide dismutase and glutathione reductase activities in Scots pine needles," Journal of Experimental Botany, vol. 44, no. 2, pp. 463-470, 1993.

[20] R. G. Alscher, "Biosynthesis and antioxidant function of glutathione in plants," Physiologia Planatarum, vol. 77, no. 3, pp. 457-464, 1989.

[21] M. A. Moritz and D. C. Odion, "Examining the strength and possible causes of the relationship between fire history and Sudden Oak Death," Oecologia, vol. 144, no. 1, pp. 106-114, 2005.

[22] H. Marschner, Mineral Nutrition of Higher Plants, Academic, London, UK, 2nd edition, 1995.

[23] E. J. Holzmueller, S. Jose, and M. A. Jenkins, "The relationship between fire history and an exotic fungal disease in a deciduous forest," Oecologia, vol. 155, no. 2, pp. 347-356, 2008.

[24] M. W. Schwartz, S. M. Hermann, and C. S. Vogel, "The catastrophic loss of Torreya taxifolia: assessing environmental induction of disease hypotheses," Ecological Applications, vol. 5, no. 2, pp. 501-516, 1995.

[25] S. Roche, J. M. Koch, and K. W. Dixon, "Smoke enhanced seed germination for mine rehabilitation in the southwest of Western Australia," Restoration Ecology, vol. 5, no. 3, pp. 191203, 1997.

[26] G. R. Flematti, E. L. Ghisalberti, K. W. Dixon, and R. D. Trengove, "A compound from smoke that promotes seed germination," Science, vol. 305, no. 5686, p. 977, 2004.

[27] N. Jain, G. D. Ascough, and J. Van Staden, "A smokederived butenolide alleviates $\mathrm{HgCI}_{2}$ and $\mathrm{ZnCI}_{2}$ inhibition of water uptake during germination and subsequent growth of tomato-possible involvement of aquaporins," Journal of Plant Physiology, vol. 165, no. 13, pp. 1422-1427, 2008.

[28] S. M. Cooper and N. Owen-Smith, "Condensed tannins deter feeding by browsing ruminants in a South African savanna," Oecologia, vol. 67, no. 1, pp. 142-146, 1985.

[29] J. R. Donaldson and R. L. Lindroth, "Genetics, environment, and their interaction determine efficacy of chemical defense in trembling aspen," Ecology, vol. 88, no. 3, pp. 729-739, 2007.

[30] C. B. Purrington, "Costs of resistance," Current Opinion in Plant Biology, vol. 3, no. 4, pp. 305-308, 2000.

[31] S. Y. Strauss, J. A. Rudgers, J. A. Lau, and R. E. Irwin, "Direct and ecological costs of resistance to herbivory," Trends in Ecology and Evolution, vol. 17, no. 6, pp. 278-285, 2002.

[32] R. B. Taylor, E. Sotka, and M. E. Hay, "Tissue-specific induction of herbivore resistance: seaweed response to amphipod grazing," Oecologia, vol. 132, no. 1, pp. 68-76, 2002.

[33] J. P. Bryant, T. P. Clausen, P. B. Reichardt, M. C. McCarthy, and R. A. Werner, "Effect of nitrogen fertilization upon the secondary chemistry and nutritional value of quaking aspen (Populus tremuloides Michx.) leaves for the large aspen tortrix (Choristoneura conflictana (Walker))," Oecologia, vol. 73, no. 4, pp. 513-517, 1987.

[34] H. E. Brown, "Gamble oak in west-central Colorado," Ecology, vol. 39, no. 2, pp. 317-327, 1958.

[35] L. B. Lentile, P. Morgan, and A. T. Hudak, "Post-fire burn severity and vegetation response following eight large wildfires across the Western United States," Fire Ecology, vol. 3, no. 1, pp. 91-108, 2007. 
[36] B. P. Kurzel, T. T. Veblen, and D. Kulakowski, "A typology of stand structure and dynamics of Quaking aspen in northwestern Colorado," Forest Ecology and Management, vol. 252, no. 1-3, pp. 176-190, 2007.

[37] J. P. Kimmins, Forest Ecology: A Foundation for Sustainable Forest Management and Environmental Ethics in Forestry, Prentice Hall, Upper Saddle River, NJ, USA, 3rd edition, 2004.

[38] "Smoke management guide for prescribed and wildland fire," in Smoke Source Characteristics, C. C. Hardy, R. D. Ottmar, J. L. Peterson, J. E. Core, and P. Seamon, Eds., pp. 89-105, National Wildfire Coordination Group, Boise, Idaho, USA, 2001 edition, 2001.

[39] T. D. Sharkey, C. J. Bernacchi, G. D. Farquhar, and E. L. Singsaas, "Fitting photosynthetic carbon dioxide response curves for C3 leaves," Plant, Cell and Environment, vol. 30, no. 9, pp. 1035-1040, 2007.

[40] L. J. Porter, L. N. Hrstich, and B. G. Chan, "The conversion of procyanidins and prodelphinidins to cyanidin and delphinidin," Phytochemistry, vol. 25, no. 1, pp. 223-230, 1985.

[41] R. L. Lindroth, K. K. Kinney, and C. L. Platz, "Responses of deciduous trees to elevated atmospheric $\mathrm{CO} 2$ : productivity, phytochemistry, and insect performance," Ecology, vol. 74, no. 3, pp. 763-777, 1993.

[42] M. L. Gumpertz and C. Brownie, "Repeated measures in randomized block and split-plot experiments," Canadian Journal of Forest Research, vol. 23, no. 4, pp. 625-639, 1993.

[43] H. Saxe, "Effects of NO, NO2 and CO2 on net photosynthesis, dark respiration and transpiration of pot plants," New Phytologist, vol. 103, no. 1, pp. 185-197, 1986.

[44] J. W. Swanepoel, G. H. J. Krüger, and P. D. R. van Heerden, "Effects of sulphur dioxide on photosynthesis in the succulent Augea capensis Thunb," Journal of Arid Environments, vol. 70, no. 2, pp. 208-221, 2007.

[45] P. Berrang, D. F. Karnosky, and J. P. Bennett, "Natural selection for ozone tolerance in Populus tremuloides: and evaluation of nationwide trends," Canadian Journal of Forest Research, vol. 21, no. 7, pp. 1091-1097, 1991. 

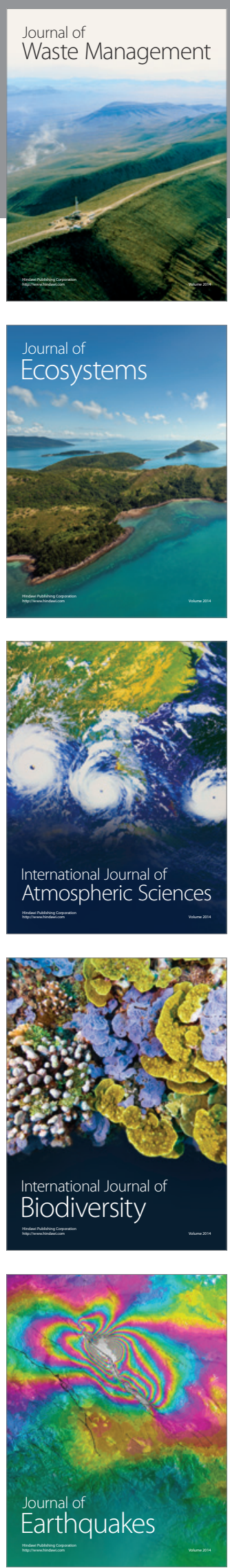
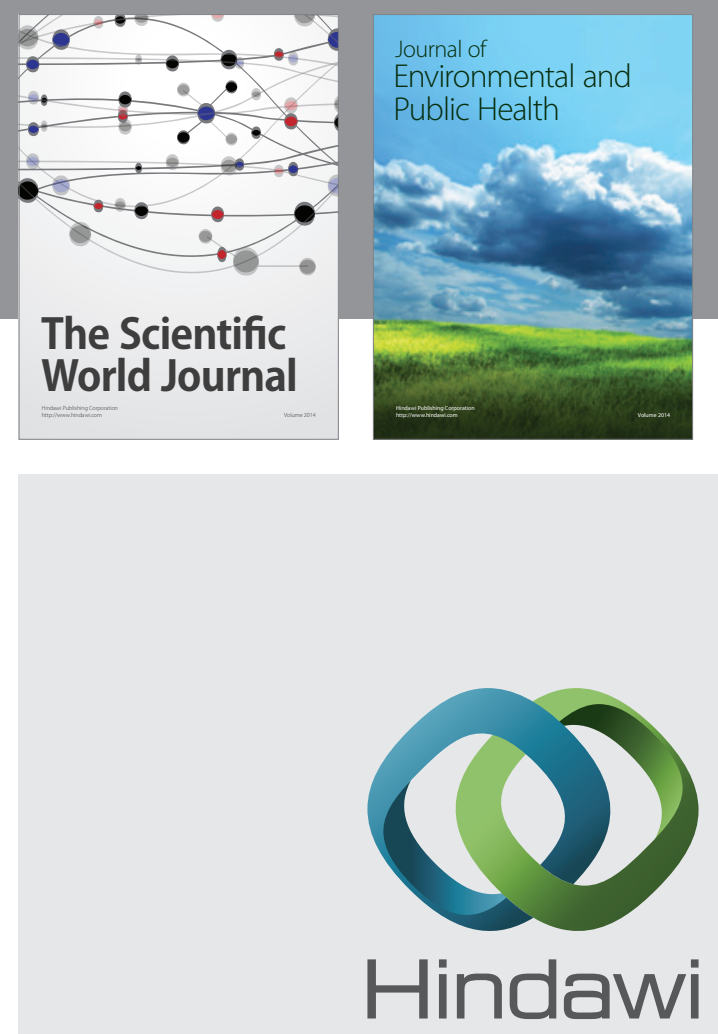

Submit your manuscripts at

http://www.hindawi.com
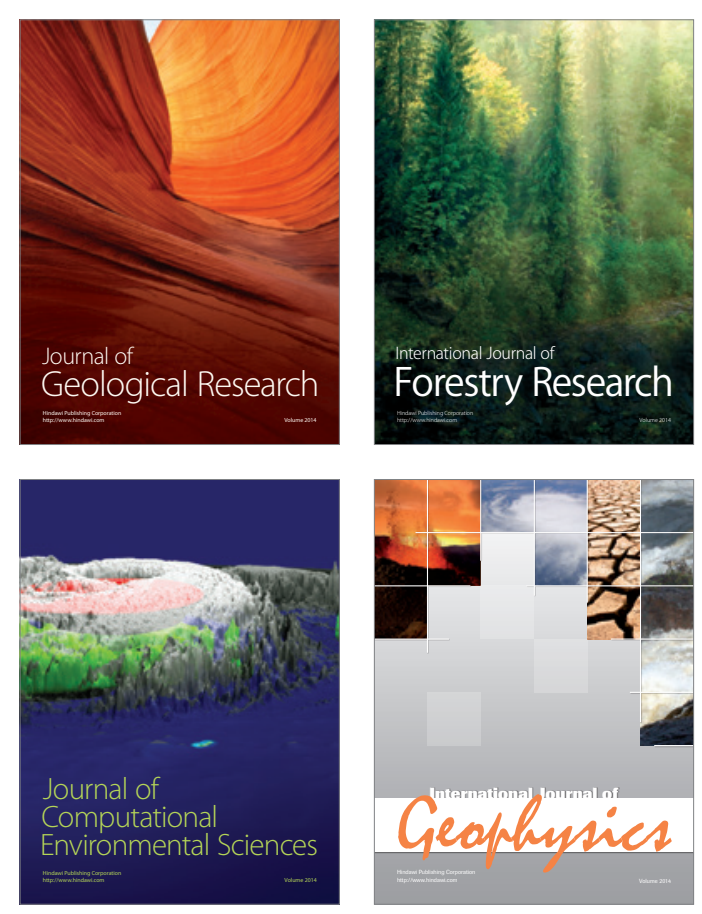
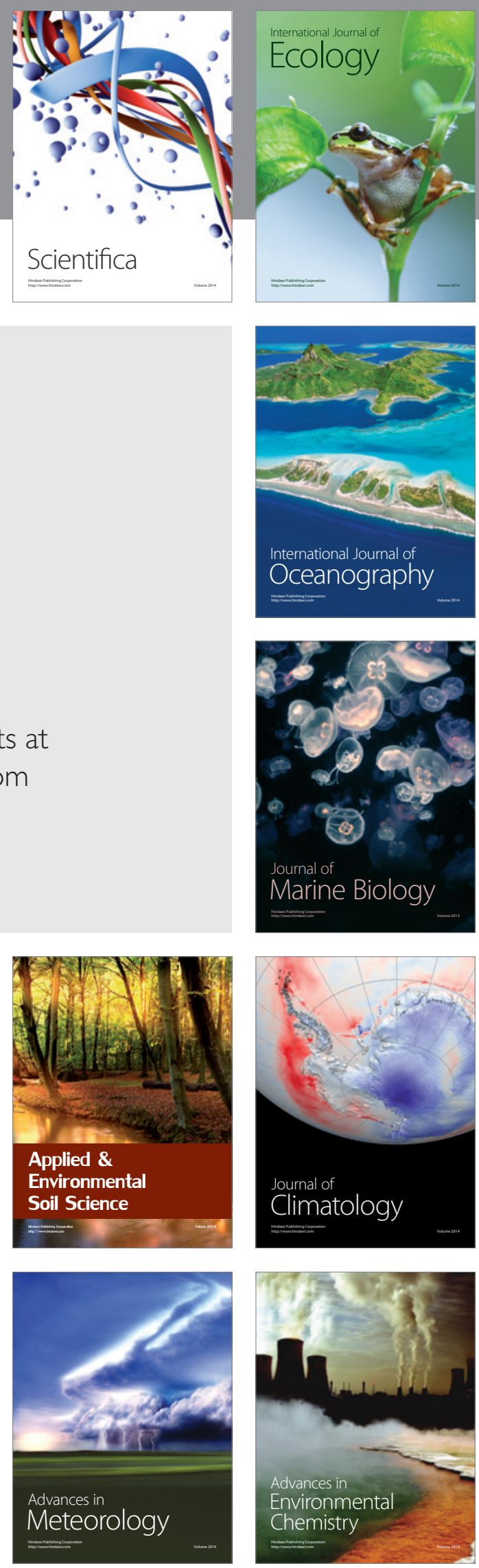